\title{
MicroRNA 363 mediated positive regulation of c-myc translation affect prostate cancer development and progress
}

\author{
Y. $\mathrm{CHEN}^{1,2, *}, \mathrm{X} . \mathrm{LU}^{2}, \mathrm{~B} . \mathrm{WU}^{2}, \mathrm{Y} . \mathrm{SU}^{2}, \mathrm{~J} . \mathrm{LI}^{2}, \mathrm{H} . \mathrm{WANG}^{1, *}$ \\ ${ }^{1}$ Department of Urology, Tang Du hospital, Fourth Military Medicine University, Xian, 710038, Shannxi Province, PR China; ${ }^{2}$ Department of \\ Urology, 323 hospital of PLA, Xian, 710054, Shannxi Province, PR China
}

*Correspondence: hewangxian@126.com,yongchenxa@163.com

Received April 24, 2014 / Accepted August 6, 2014

\begin{abstract}
Prostate cancer $(\mathrm{CaP})$ is the sixth most significant cancer killer of men in China. In this study, the potential role of micro363 (miR-363) in CaP development and progression was investigated. Pri-miR-363 or anti-miR-363 was transfected into the $\mathrm{CaP}$ cells line PC-3 cells. Cell proliferation, transformation property, and epithelial-to-mesenchymal transition (EMT) were evaluated by MTT, clonogenic assay, colony formation in soft agar and western blotting, respectively. The expression and involvement of c-myc, a downstream target of miR-363 were also determined. The results showed that endogenous expression of miR-363 was significantly increased in CaP cells compared with normal prostate cells. High expression of miR-363 in PC-3 cells through transfection induces cell proliferation and positively regulates cell transformation property as well as promotes EMT of PC-3 cells. Through knockdown of c-myc, the results also showed that c-myc was involved in the regulation of biological function of PC-3 cells by miR-363. Taken together, this study adds support to the potential role of miR-363 in the diagnosis and treatment of $\mathrm{CaP}$.
\end{abstract}

Key words: prostate cancer, transformation property, proliferation, micro-363, epithelial-to-mesenchymal transition

Prostate cancer $(\mathrm{CaP})$ is the sixth most significant cancer killer of men in China. In 2012, the incidence of CaP in the registration area of China was 9.92/100000 [1]. CaP is highly heterogeneous, ranging from asymptomatic to rapidly fatal malignancy [2]. Early diagnosis of cancer and timely detection of disease progression following either radical prostatectomy or radiation therapy are crucial for effective treatment of $\mathrm{CaP}$ and for a beneficial clinical outcome [3]. Recently, interest in alternative biomarkers for CaP, such as microRNAs (miRNAs) has been rapidly growing [4].

miRNAs are made up of -22 endogenous nucleotides [5]. These small, noncoding RNAs are important regulators of gene expression at the post-transcriptional level. through repressing target proteins. The repressive effect is mainly achieved via RNA-RNA binding at imperfect complementary sequences within the 3'-untranslated region (3'-UTR) of the target mRNA, subsequently causing either mRNA degradation or translational inhibition [6]. It has become increasingly clear that aberrant expression of miRNAs is closely associated with proliferation, invasion, metastasis, and prognosis of various cancers, including $\mathrm{CaP}$, gastric cancer, breast cancer, glioma and lung cancer [7-10]. Studies have shown that in $\mathrm{CaP}, 30 \%$ of epigenetic silencing regions contain the loci of miRNAs, and differences in the expression patterns of many miRNAs in $\mathrm{CaP}$ have been reported in different studies $[8,11-13]$. miRNAs in CaP tissues might be promising biomarkers that might be a useful marker for the prognosis of $\mathrm{CaP}$.

Several studies have revealed the possible regulatory functions of miR-363 in diverse biological processes. In human uterine leiomyoma and CD4+ and CD8+ cells of cord blood, miR-363 is significantly up-regulated. However, it is down-regulated in CD4+ T cells of patients with rheumatoid arthritis. miR-363 is down-regulated in human papillomavirus (HPV)-transfected keratinocyte HaCaT cells, but up-regulated in HPV-positive pharyngeal squamous cancers [14]. miR-363 is also associated with many cancers, including gastric cancer, hepatocarcinoma, and neuroblastoma [14-16]. In aggressive gastric cancer, miR-363 affects cell adhesion and migration through targeting disintegrin and metalloproteinase 15 (ADAM15) [17]. In HPV-positive squamous cell carcinoma of the head and neck, it has also been shown to 
regulate myosin-1b (MYO1B), which modulates cell motility and migration[18].

However, to the best of our knowledge, the potential role of miR-363 in CaP development and progression is still unclear. In this study, pri-miR-363 or anti-miR-363 was transfected into the CaP cells PC-3 cells. Cellular activities including proliferation, transformation property, and epithelial-tomesenchymal transition (EMT) were all evaluated. We also determined the downstream target of miR-363 in CaP cells. This study adds support to the potential use of miR-363 as a biomarker or target for the diagnosis and treatment of $\mathrm{CaP}$.

\section{Materials and methods}

Cell culture. Human CaP cell lines 22Rv1, LNCap, DU145, and PC-3 and normal prostate epithelial cell line RWPE-1 were obtained from American Type Culture Collection (ATCC, Manassas, VA, USA). All cells were cultured in RPMI-1640 (Gibco, Grand Island, NY, USA) supplemented with 10\% fetal bovine serum (Gibco, Grand Island, NY, USA) and penicillin (100 U/ml, TaKaRa, Dalian, China) and were maintained under an atmosphere containing $5 \% \mathrm{CO}_{2}$.

Total RNA extraction and miRNA quantitative real-time reverse transcription polymerase chain reaction (RT-PCR). Total RNA was extracted from cultured cells using Trizol Reagent (Invitrogen, CA, USA). cDNA was synthesized using M-MLV MicroRNA Reverse Transcription Kit (Promega, Madison, WI, USA) from 10ng of total RNA. Real-time RT-PCR was performed with SYBRH Premix Ex TaqTM (TaKaRa, Biotech Co., Ltd, Dalian, China) and specific primer designed for miR-363/c-myc to detect mature miR-363 or cmyc. miRNA expression was normalized with the level of U6. PCR was performed under the following conditions: $94^{\circ} \mathrm{C}$ for $4 \mathrm{~min}$, followed by 40 cycles at $94^{\circ} \mathrm{C}$ for $30 \mathrm{~s}, 50^{\circ} \mathrm{C}$ for $30 \mathrm{~s}$, and $72^{\circ} \mathrm{C}$ for $40 \mathrm{~s}$. Each sample was run in triplicate. The primers used in this study were as following: GAPDH: sense 5'-ACC CAC TCC TCC ACC TTT G-3', antisense:5'-CTC TTG TGC TCT TGC TGG G-3'; miR-363: sense: 5'-GTC GTA TCC AGT GCA GGG TCC GAG GTA TTC GCA CTG GAT ACG ACT ACA GA-3', antisense: 5'-TCG AAT TGC ACG GTA TCC ATC-3';U6: 5' - AAC GCT TCA CGA ATT TGC GT-3', antisense:5' - CTC GCT TCG GCA GCA CA-3'; c-myc: sense: 5'-TGG TGC TCC ATG AGG AGA CA-3', 5'-GTG TTT CAA CTG TTC TCG TC-3'.

Cell transfection. The recombinant miR-363-expressing adenoviral plasmid (and recombinant synthetic negative control miRNAs, synthetic anti-miR-363 sequence and synthetic anti-miR-363 negative control adenoviral plasmid) were purchased from Genechem Ltd. (Shanghai, China). Transfections PC-3 cells was performed according to the manufacturer's protocol as previously described [19]. Briefly, PC-3 cells were plated in six-well plates and grown to $60-80 \%$ confluence. Each well received $10 \mu \mathrm{L}$ of lipofectamine reagent (Amersham, Piscataway, NJ, USA) and pri-miR-363, synthetic negative control miRNAs (miR-363-NC), synthetic anti-miR-363 sequence (anti-miR-363), or synthetic anti-miR-363 negative control (anti-miR-363-NC), to a final concentration of $50 \mathrm{nM}$. For other experiments, c-myc-shRNA vectors were transfected into cells to produce c-myc siRNA stable expression cells. ( c-myc shRNA: 5'-CCA TAA TGT AAA CTG CCT CAA CTC GAG TTG AGG CAG TTT ACA TTA TGG TTT TT-3').

Western blot analysis. Whole cell lysates were prepared as described previously [20]. PC-3 cells in different groups were lysed with RIPA buffer and the protein concentration of cell lysates was determined using the BCA assay. Forty micrograms of total protein per well were separated by SDS-PAGE on $10 \%$ polyacrylamide gels and transferred onto PVDF membranes. After blocking with $0.5 \%$ non-fat milk, the target proteins were probed with 1:1000 mouse anti-human c-myc, E-cadherin, plakoglobin, $\mathrm{N}$-cadherin or $\beta$-actin antibody overnight at $4^{\circ} \mathrm{C}$. After washing thrice (10 min/time) with $1 \times$ PBS-Tween 20 , the membranes were incubated with HRP-conjugated sheep anti-mouse IgG antibody (1:4000 diluted in PBS) at room temperature for $1 \mathrm{~h}$ and washed again. The reactive bands were detected by enhanced chemiluminescence (ECL) according to the manufacturer's protocol.

MTT assays. PC- 3 cells transfected with different miRNAs (or together with c-myc-specific siRNA) were seeded onto 24 -well plates at a density of $1 \times 10^{4}$ cells per well in triplicate. Cell viability was assessed by 3-(4,5-dimethyl-2-thiazolyl)-2, 5-diphenyl tetrazolium bromide (MTT; Sigma-Aldrich, St. Louis, MO, USA) method. After incubation for $48 \mathrm{~h}$, $10 \mu \mathrm{L}$ of MTT $(0.5 \mathrm{mg} / \mathrm{ml})$ were added to each well for an additional $3 \mathrm{~h}$ of incubation. Then, $250 \mu \mathrm{L}$ of dimethylsulf oxide (DMSO) were added to each well and the absorbance at $490 \mathrm{~nm}$ was measured using a microplate enzyme-linked immunosorbent assay reader (Biochrom EZ Read 400, Cambridge, UK).

Clonogenic assay. Clonogenic assays were performed as previously described [21]. PC-3 cells suspended in RPMI 1640 media with $10 \%$ fetal bovine serum (FBS) were plated in six-well plates $\left(1 \times 10^{3}\right.$ cells/well $)$ and incubated for 10 days. Colonies were fixed and stained with $0.005 \%$ crystal violet in $70 \%$ methanol overnight. Images of the colonies were taken with the Bio-Rad Gel Doc XR+ Imaging System, and quantitated using Bio-Rad Quantity One Gel Doc version 4.6.9 software. All cultures were performed in triplicate and the experiments for each miRNA were repeated three times.

Anchorage-independent colony growth. Anchorageindependent growth was measured by assessing colony formation in soft agar, as previously described [22]. PC-3 cells were seeded $\left(1 \times 10^{5}\right.$ cells/well $)$ in $0.35 \%$ agar mixed with RPMI1640 medium in a six-well plate and cultured at $37^{\circ} \mathrm{C}$ for 10days. The ability to form colonies in soft agar was measured by counting the number of colonies under a stereoscopic microscope in triplicate of a six-well plate. Data shown represent means \pm standard deviations (SDs) of three independent experiments. 
Statistical analysis. The two-tailed Student's t-test was used to evaluate the significance of the differences between two groups; $\mathrm{P}$ values $<0.05$ were considered significant.

\section{Results}

miR-363 expression in CaP cells. To check whether miR-363 participates in tumor progression of $\mathrm{CaP}$, we first determined the relative levels of endogenous miR-363 using miRNA quantitative real-time PCR in four human $\mathrm{CaP}$ cell lines including 22Rv1, LNCap, DU145, and PC-3. Normal prostate epithelial cell line RWPE-1 was used as control. As shown in figure 1, the expression of miR-363 in four CaP cells was significantly increased compared with the normal cell line RWPR-1. PC-3 cells showed the highest endogenous miR-363 expression. Since PC-3 cell is androgen-receptor negative, in this study, PC-3 and LNCap (androgen-sensitive human prostate cancer cell line) cells were chosen for subsequent investigation.

High expression of miR-363 in PC-3 cells induces cell proliferation. To determine the potential biological function of miR-363 in CaP, pri-miR363, anti-miR363 or scrambled control was stably transfected into PC-3 cells to overexpression or knockdown in PC-3 cells. miRNA quantitative RT-PCR was performed $24 \mathrm{~h}, 48 \mathrm{~h}, 72 \mathrm{~h}$ after transfection. As shown in figure $2 \mathrm{~A}, 48 \mathrm{~h}$ after transfection, miR-363 expression was significantly increased in pri-miR363-transfected PC-3 cells and was significantly reduced in anti-miR363-transfected PC-3 cells compared with the control group. Similar results were observed $72 \mathrm{~h}$ after transfection.

We then determined cell proliferation of different transfection groups by the MTT assay $72 \mathrm{~h}$ after transfection. As shown in figure $2 \mathrm{~B}$, compared with cells at resting and cells transfected with pre-miR-363-NC, overexpression of miR363 significantly increased PC-3 cell proliferation. While cell proliferation of anti-pre-miR-363 transfected PC- 3 cells were significantly decreased.

miR-363 positively regulates transformation property of PC-3 cells. To better elucidate the effect of miR-363 on division property of PC-3 cells, we further performed clonogenic assays to determine the ability of each cell to undergo "unlimited" division. As shown in figure $3 \mathrm{~A}$, overexpression of miR-363 significantly increased the number of colonies to $187 \%$ of that at resting. On the other hand, knockdown of miR-363 significantly reduced the number of colonies to $59 \%$ of that at resting. All these results suggested that the pro-tumor property of miR-363.

Furthermore, to examine anchorage-independent growth ability, we performed soft agar colony formation assays, which are an accepted in vitro assay for detecting cell malignancy. PC-3 cells transfected with different miRNAs were plated in soft agar and incubated for 2 weeks. As shown in figure 4, transfection of pri-miR-363 significantly increased anchorageindependent growth. Compared with the control group, the number of colonies was significantly increased by about $48 \%$. Similar results were also observed in anti-miR-363 transfected

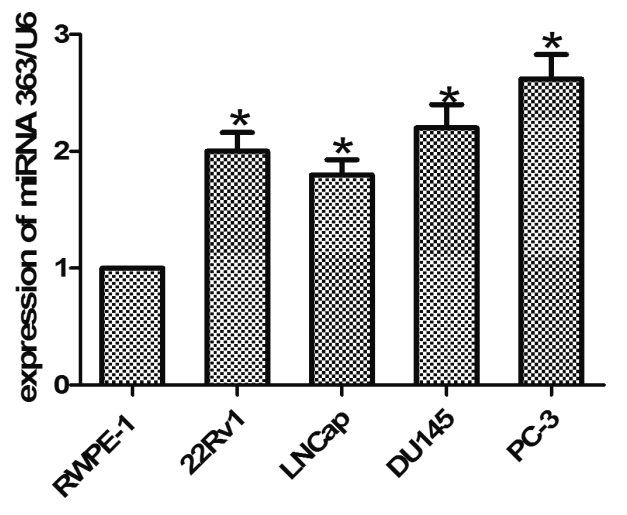

Figure 1. Endogenous expression of miR-363 in four human CaP cell lines by miRNA quantitative real-time PCR. ${ }^{\star} \mathrm{P}<0.05$ vs. RWPE- 1 cells.
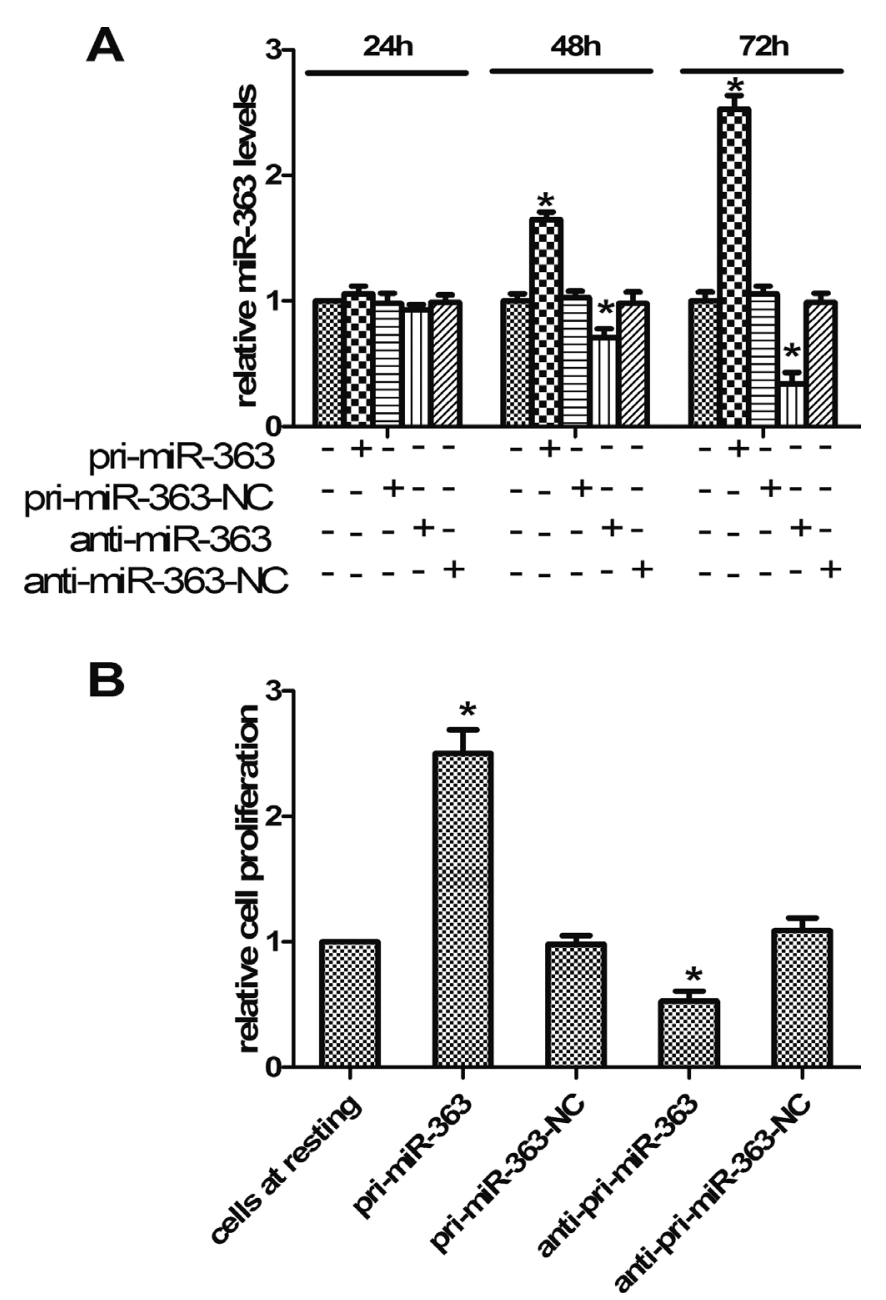

Figure 2. High expression of miR-363 in PC-3 cells induces cell proliferation. PC-3 cells were transfected with different miRNAs: (A) miR-363 expression in PC-3 cells of different transfection groups were detected at 24h, 48h and 72h after transfection, (B) Proliferation of PC-3 cells transfected with different miRNAs were detected by the MTT assay $72 \mathrm{~h}$ after transfection. ${ }^{\star} \mathrm{P}<0.05$, significant differences were observed compared with cells at resting or cells transfected with controls. 
A

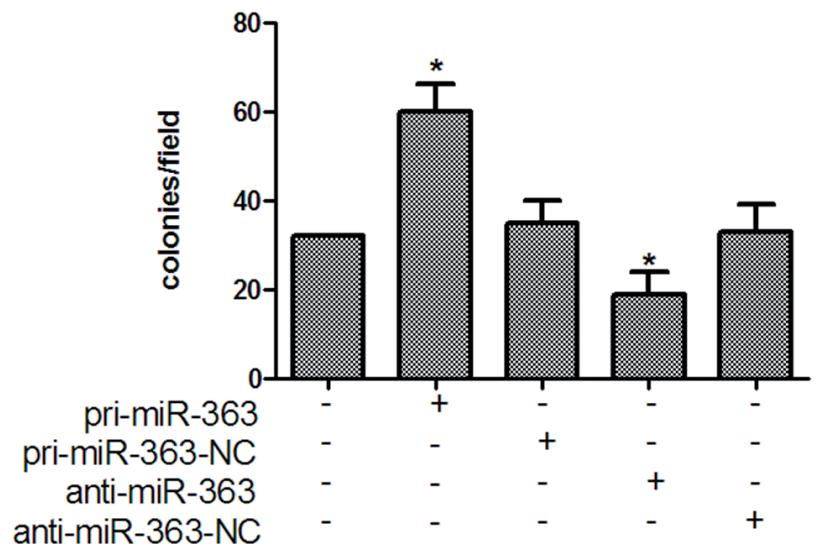

B
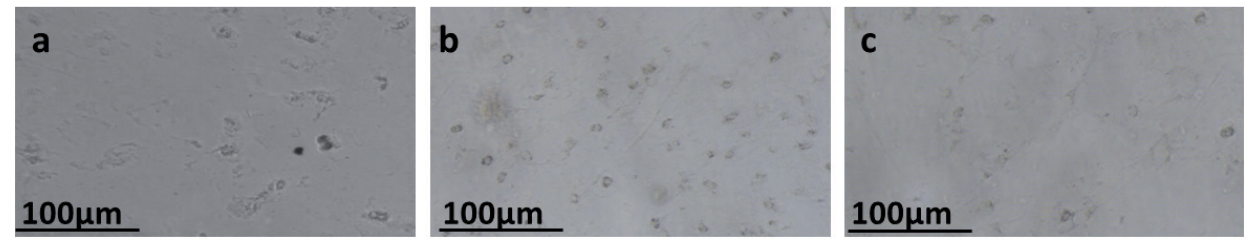

Figure 3 Overexpression/knockdown of miR-363 significantly increased/reduced the number of colonies by clonogenic assays. (A) the number of colonies of different group. (B) a: cells at resting, b: PC-3 cells transfected with pri-miR-363, c: PC-3 cells transfected with anti-pri-miR-363. ${ }^{\star} \mathrm{P}<0.05$, significant differences were observed compared with cells at resting.

A

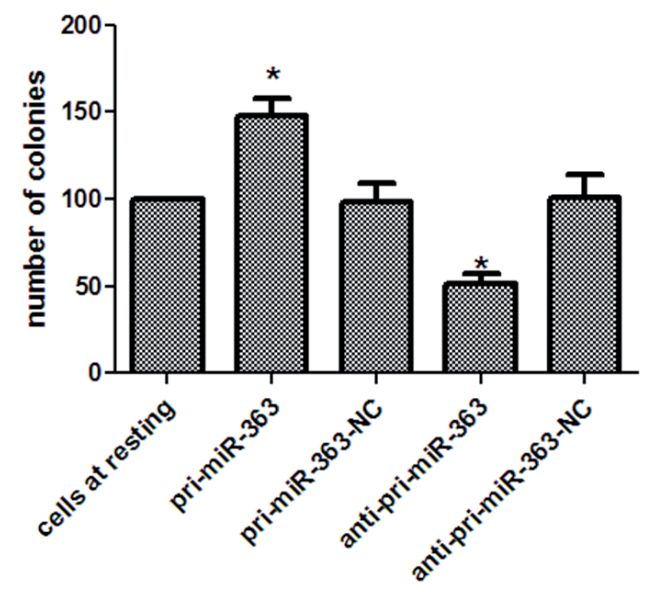

B
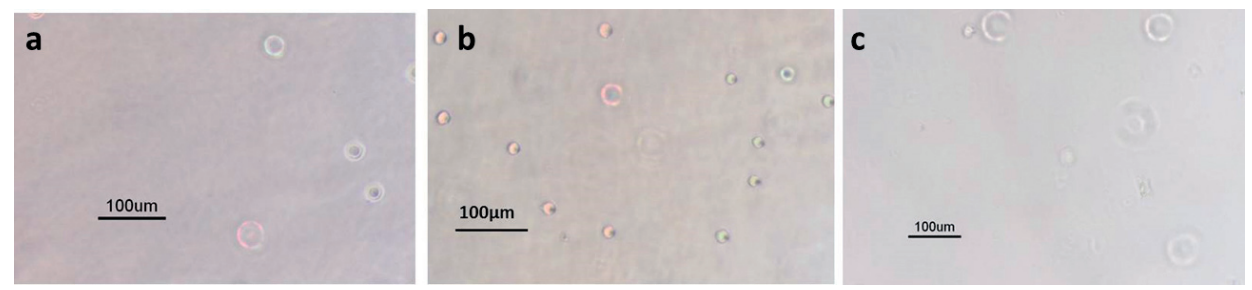

Figure 4 Overexpression/knockdown of miR-363 significantly increased/reduced anchorage-independent growth of PC-3 cells by soft agar colony formation assays. (A) anchorage-independent growth of PC-3 cells. (B) a: PC-3 cells at resting, b: PC-3 cells transfected with pri-miR-363, c: PC-3 cells transfected with anti-pri-miR-363. ${ }^{\star} \mathrm{P}<0.05$, significant differences were observed compared with cells at resting. 
PC-3 cells: the number of colonies was reduced by nearly $50 \%$ compared with control. All these results indicated that miR-363 positively regulated the transformation property of PC-3 cells.

High expression of miR-363 in PC-3 cells promotes EMT of PC-3 cells. Next, we asked whether miR-363 was involved in the control of EMT. The levels of epithelial markers E-cadherin and plakoglobin, together with mesenchymal markers $\mathrm{N}$ cadherin were determined by Western blotting. As shown in figure 5, pri-miR-363 transfection decreased the expression of E-cadherin and plakoglobin and increased the expression of $\mathrm{N}$-cadherin while anti-miR-363 transfection resulted in opposite expression of these markers.

miR-363 regulates biological function of PC-3 cells through c-myc. To elucidate the molecular mechanism by which miR-363 positively regulates PC-3 cell proliferation and transformation property, we determined the expression of c-myc, a downstream target oncogene of miR-363. As shown in figure $6 \mathrm{~A}$ and figure $6 \mathrm{~B}, \mathrm{mRNA}$ and protein levels of $\mathrm{c}-$ myc in pri-miR363-transfected PC-3 cells were significantly increased. To further confirm the role of c-myc, c-myc-specific siRNAs were transfected into pri-miR-363-transfected PC-3 cells and c-myc levels were significantly decreased (figure $6 \mathrm{C}$ ). In normal cells transfected with c-myc-specific siRNAs, cell proliferation were decrease. However, no significant difference was found. c-myc silencing significantly deceased miR-363 overexpression induced PC-3 cell proliferation and colony formation. All these results suggested that c-myc was a downstream target of miR-363 in regulating the biological function of PC-3 cells.

\section{Discussion}

The various genetic alterations in $\mathrm{CaP}$ play important roles in the specific activity of miRNAs, as $30 \%$ of epigenetic silenced regions contained the loci of miRNAs. Recent studies have demonstrated that aberrant expression of miRNAs is closely associated with the development, invasion, metastasis and prognosis of $\mathrm{CaP}$ [23]. The exact function of miR-363 in $\mathrm{CaP}$ progression, however, has not been elucidated. We detected the expression of miR-363 in different $\mathrm{CaP}$ cells and normal prostate cells, and found that the $\mathrm{CaP}$ cells showed significantly increased miR-363 expression. We supposed that alterations in miR-363 might contribute to the development and progression of CaP. In this study, we found that miR-363 played critical roles in activities of PC-3 cells. Using miRNA quantitative real-time RT-PCR, we showed that miR-363 was significantly increased in PC-3 cells, and high expression of miR-363 in PC-3 cells could induce PC-3 cell proliferation. We also demonstrated that high expression of miR-363 in PC-3 cells had pro-tumor function using clonogenic formation assay and anchorage-independent cell growth assay. The change in expression of E-cadherin and plakoglobin also suggested that miR-363 participated in the EMT event. However, we did experiments only in PC-3 cells which were androgen receptor
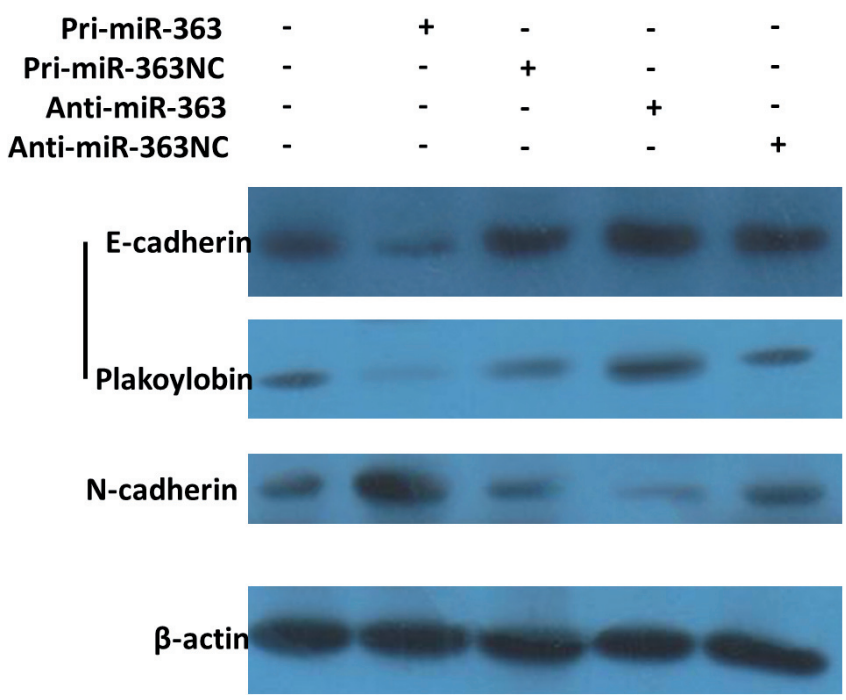

Figure 5 miR-363 enhances EMT of PC- 3 cells. The levels of E-cadherin, plakoglobin and $\mathrm{N}$-cadherin in different $\mathrm{PC}-3$ cells were determined by Western blotting. ${ }^{*} \mathbf{P}<0.05$, significant differences were observed compared with cells at resting and cells transfected with c-myc-specific siRNA. $\# \mathbf{P}<0.05$, significant differences were observed compared with cells at resting and cells transfected with pri-miR-363.

negative. Further studies were expected to investigate the role of miR-363 in other different kinds of cells.

MicroRNAs regulate gene expression by affecting the stability or translation efficiency of target mRNAs. Up to 50 miRNAs have been reported to be significantly expressed in human $\mathrm{CaP}$ [24]. Overexpression of the oncomirs epigenetically silences apoptosis-related genes, inducing tumor growth and metastasis, while loss of tumor suppressor miRNAs is another mechanism related to the progression of $\mathrm{CaP}[25,26]$. In this study, miR-363 expression was measured in CaP cells. miRNA-363 shows different expression patterns in different diseases and different cells, and thus performs diverse functions. Through a recombinant miR-363-expressing adenoviral plasmid, high miR-363 was stably expressed in PC-3 cells. High overexpressed miR-363 significantly increased cell proliferation. Clonogenic assay showed that high overexpression of miR-363 promoted the ability of each PC-3 cell to undergo "unlimited" division. Meantime, we found that miR-363 overexpression promoted PC-3 cell malignancy in vitro which was assessed using soft agar colony formation assay. The decreased E-cadherin and plakoglobin and increased N-cadherin also suggested that miR-363 was involved in the EMT event. Collectively, these findings prove the involvement of miR-363 in the progression, invasion, and metastasis of $\mathrm{CaP}$.

In this study, using co-transfection of miR-363 and c-mycspecific siRNAs, we also found that c-myc, a downstream oncogene of miRNAs, mediated the function of miR-363. Cmyc is critical for development and survival and is well-known for its regulation of proliferation, differentiation, and oncogenesis [27]. Deregulation of c-myc acts as an oncogenic driver 
in many cancers, including $\mathrm{CaP}$ [28]. For example, inhibition of c-myc translation causes significant growth inhibition and apoptosis in $\mathrm{CaP}$ cells and in subcutaneous tumor xenografts. Another study showed that antisense c-myc retroviral vector suppressed established human CaP [29]. Through microRNA. org (http://www.microrna.org/microrna/getMirnaForm.do), we found that c-myc was not a direct target of miR-363. Studies from Han Han et al. have shown that in human HCC, miR$363-3 p$ destabilizes myc indirectly by directly targeting and inhibiting USP28, which promotes the proteasome-mediated degradation of myc protein[16]. However, in prostate cancer, how miR-363 affected c-myc expression were barely studied. Further studies are need to investigate the exact signaling pathways involving miR-363 and c-myc.
A
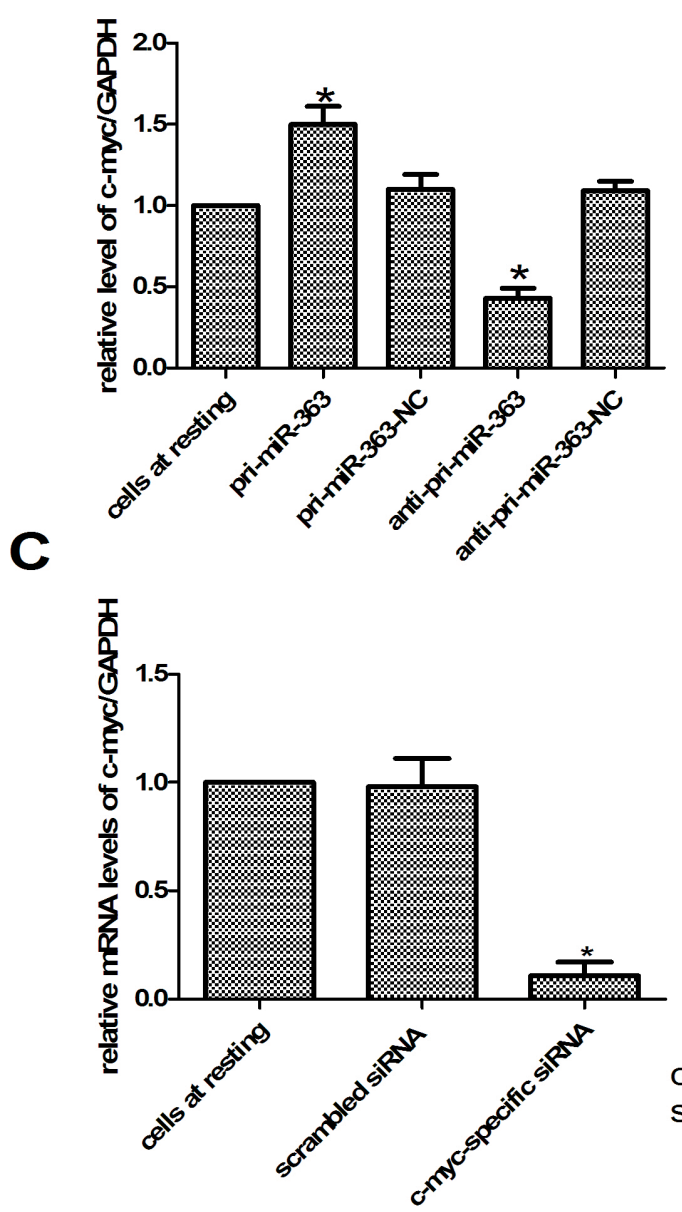

E

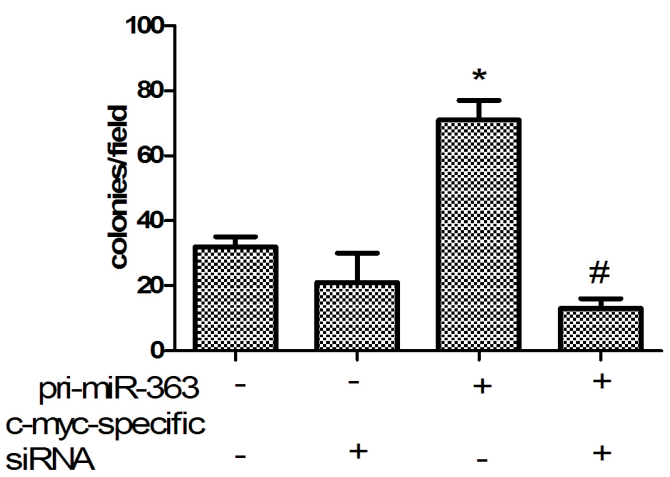

B

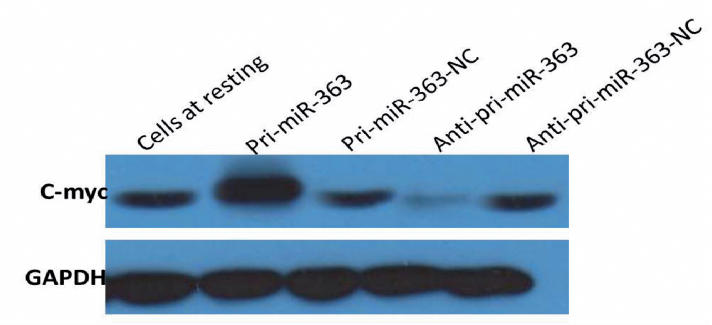

D

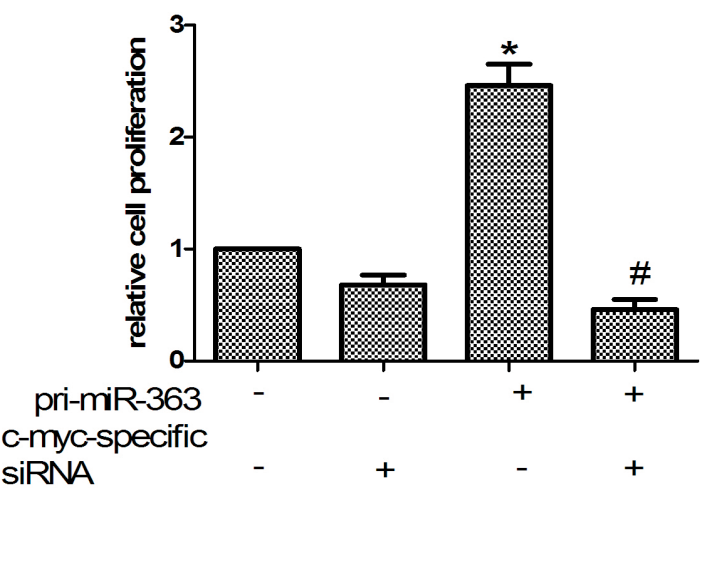

Figure 6 miR-363 regulates biological function of PC-3 cells through c-myc. (A/B): mRNA/protein levels of c-myc in PC-3 cells with different transfections. $(\mathrm{C})$ : relative mRNA levels of $\mathrm{c}$-myc in c-myc shRNA stable expression cells; (D/E): c-myc silencing abolished miR-363 overexpression induced PC-3 cell proliferation (D) and colony formation (E). 
Our data here provide evidence that the expression of miR363 is increased in CaP cells. The increased miR-363 promotes PC-3 cell activities including proliferation, transformation ability and EMT, and the oncogene c-myc is involved. A better understanding of miR-363-mediated molecular mechanisms in $\mathrm{CaP}$ could potentially provide novel therapeutic strategies against $\mathrm{CaP}$.

\section{References}

[1] CENTER MM, JEMAL A, LORTET-TIEULENT J, WARD E, FERLAY J et al.. International variation in prostate cancer incidence and mortality rates. European urology 2012; 61: 1079-1092. http://dx.doi.org/10.1016/j. eururo.2012.02.054

[2] HUGHES C, MURPHY A, MARTIN C, SHEILS O, O'LEARY J. Molecular pathology of prostate cancer. Journal of clinical pathology 2005; 58: 673-684. http://dx.doi.org/10.1136/ jcp.2002.003954

[3] CHORNOKUR G, DALTON K, BORYSOVA ME, KUMAR NB. Disparities at presentation, diagnosis, treatment, and survival in African American men, affected by prostate cancer. The Prostate 2011; 71: 985-997. http://dx.doi.org/10.1002/ pros. 21314

[4] LU J, GETZ G, MISKA EA, ALVAREZ-SAAVEDRA E, LAMB J et al.. MicroRNA expression profiles classify human cancers. nature 2005; 435: 834-838. http://dx.doi.org/10.1038/ nature 03702

[5] CALIN GA, CROCE CM. MicroRNA signatures in human cancers. Nature Reviews Cancer 2006; 6: 857-866. http:// dx.doi.org/10.1038/nrc1997

[6] OKAMURA K, PHILLIPS MD, TYLER DM, DUAN H, CHOU Y-T et al.. The regulatory activity of microRNA* species has substantial influence on microRNA and 3' UTR evolution. Nature structural \& molecular biology 2008; 15 : 354-363. http://dx.doi.org/10.1038/nsmb.1409

[7] IORIO MV, FERRACIN M, LIU C-G, VERONESE A, SPIZZO R et al.. MicroRNA gene expression deregulation in human breast cancer. Cancer research 2005; 65: 7065-7070. http://dx.doi.org/10.1158/0008-5472.CAN-05-1783

[8] CATTO JW, ALCARAZ A, BJARTELL AS, DE VERE WHITE $\mathrm{R}$, EVANS CP et al.. MicroRNA in prostate, bladder, and kidney cancer: a systematic review. European urology 2011; 59: 671-681. http://dx.doi.org/10.1016/j.eururo.2011.01.044

[9] NOVAKOVA J, SLABY O, VYZULA R, MICHALEK J. MicroRNA involvement in glioblastoma pathogenesis. Biochemical and biophysical research communications 2009; 386: 1-5. http://dx.doi.org/10.1016/j.bbrc.2009.06.034

[10] LI M, LI J, DING X, HE M, CHENG S-Y. microRNA and cancer. The AAPS journal 2010; 12: 309-317. http://dx.doi. org/10.1208/s12248-010-9194-0

[11] AMBS S, PRUEITT RL, YI M, HUDSON RS, HOWE TM et al.. Genomic profiling of microRNA and messenger RNA reveals deregulated microRNA expression in prostate cancer. Cancer research 2008; 68: 6162-6170. http://dx.doi. org/10.1158/0008-5472.CAN-08-0144
[12] LIU C, KELNAR K, LIU B, CHEN X, CALHOUN-DAVIS T et al.. The microRNA miR-34a inhibits prostate cancer stem cells and metastasis by directly repressing CD44. Nature medicine 2011; 17: 211-215. http://dx.doi.org/10.1038/nm.2284

[13] KIM WT, KIM W-J. MicroRNAs in prostate cancer. Prostate international 2013; 1: 3. http://dx.doi.org/10.12954/ PI.12011

[14] QIAO J, LEE S, PAUL P, THEISS L, TIAO J et al.. miR-335 and miR-363 regulation of neuroblastoma tumorigenesis and metastasis. Surgery 2013; 154: 226-233. http://dx.doi. org/10.1016/j.surg.2013.04.005

[15] HSU K-W, WANG A-M, PING Y-H, HUANG K-H, HUANG T-T et al.. Downregulation of tumor suppressor MBP-1 by microRNA-363 in gastric carcinogenesis. Carcinogenesis 2014; 35: 208-217. http://dx.doi.org/10.1093/carcin/bgt285

[16] HAN H, SUN D, LI W, SHEN H, ZHU Y et al.. A c-Myc-MicroRNA functional feedback loop affects hepatocarcinogenesis. Hepatology 2013; 57: 2378-2389. http://dx.doi.org/10.1002/ hep. 26302

[17] KIM CH, KIM HK, RETTIG RL, KIM J, LEE ET et al.. miRNA signature associated with outcome of gastric cancer patients following chemotherapy. BMC medical genomics 2011; 4: 79. http://dx.doi.org/10.1186/1755-8794-4-79

[18] WALD AI, HOSKINS EE, WELLS SI, FERRIS RL, KHAN SA. Alteration of microRNA profiles in squamous cell carcinoma of the head and neck cell lines by human papillomavirus. Head \& neck 2011; 33: 504-512. http://dx.doi.org/10.1002/ $\underline{\text { hed. } 21475}$

[19] MURATOVSKA A, ECCLES MR. Conjugate for efficient delivery of short interfering RNA (siRNA) into mammalian cells. FEBS letters 2004; 558: 63-68. http://dx.doi.org/10.1016/ $\underline{\text { S0014-5793(03)01505-9 }}$

[20] NAKAGAWA T, ZHU H, MORISHIMA N, LI E, XU J et al.. Caspase-12 mediates endoplasmic-reticulum-specific apoptosis and cytotoxicity by amyloid- $\beta$. Nature 2000; 403: 98-103. http://dx.doi.org/10.1038/47513

[21] FRANKEN NA, RODERMOND HM, STAP J, HAVEMAN J, VAN BREE C. Clonogenic assay of cells in vitro. Nature protocols 2006; 1: 2315-2319. http://dx.doi.org/10.1038/ nprot.2006.339

[22] HSU K-W, HSIEH R-H, WU C-W, CHI C-W, LEE Y-HW et al.. MBP-1 suppresses growth and metastasis of gastric cancer cells through COX-2. Molecular biology of the cell 2009; 20: 5127-5137. http://dx.doi.org/10.1091/mbc.E09-05-0386

[23] COPPOLA V, DE MARIA R, BONCI D. MicroRNAs and prostate cancer. Endocrine-related cancer 2010; 17: F1-F17. http://dx.doi.org/10.1677/ERC-09-0172

[24] PANG Y, YOUNG CY, YUAN H. MicroRNAs and prostate cancer. Acta biochimica et biophysica Sinica 2010; 42: 363-369. http://dx.doi.org/10.1093/abbs/gmq038

[25] SUN T, WANG Q, BALK S, BROWN M, LEE G-SM et al.. The role of microRNA-221 and microRNA-222 in androgenindependent prostate cancer cell lines. Cancer research 2009; 69: 3356-3363. http://dx.doi.org/10.1158/0008-5472.CAN08-4112

[26] VARAMBALLY S, CAO Q, MANI R-S, SHANKAR S, WANG $\mathrm{X}$ et al.. Genomic loss of microRNA-101 leads to overexpres- 
sion of histone methyltransferase EZH2 in cancer. science 2008; 322: 1695-1699. http://dx.doi.org/10.1126/science.1165395

[27] DANG CV. c-Myc target genes involved in cell growth, apoptosis, and metabolism. Molecular and cellular biology 1999; 19: $1-11$.

[28] SUN C, DOBI A, MOHAMED A, LI H, THANGAPAZHAM $R$ et al.. TMPRSS2-ERG fusion, a common genomic alteration in prostate cancer activates C-MYC and abrogates prostate epithelial differentiation. Oncogene 2008; 27: 5348-5353. http://dx.doi.org/10.1038/onc.2008.183

[29] STEINER MS, ANTHONY CT, LU Y, HOLT JT. Antisense c-myc retroviral vector suppresses established human prostate cancer. Human gene therapy 1998; 9: 747-755. http://dx.doi. org/10.1089/hum.1998.9.5-747 